\title{
Impact of Once-Daily Versus Twice-Daily Dosing Frequency on Adherence to Chronic Medications among Patients with Venous Thromboembolism
}

\author{
François Laliberté • Brahim K. Bookhart • Winnie W. Nelson • \\ Patrick Lefebvre · Jeff R. Schein · Jonathan Rondeau-Leclaire • \\ Mei Sheng Duh
}

Published online: 16 July 2013

(c) The Author(s) 2013. This article is published with open access at Springerlink.com

\begin{abstract}
Background Multiple daily dosing may be negatively associated with patient medication adherence; however, adherence-related data are lacking in a patient population with venous thromboembolism (VTE).

Objective To assess the adherence rates between oncedaily (OD) and twice-daily (BID) dosing regimens of chronic medications in patients with VTE.

Methods We analyzed the PharMetrics Integrated Claims database (claims of commercial insurers in the US) from 1 January 2004, through 31 December 2009. Adult patients with continuous insurance coverage, newly initiated on diabetes mellitus or hypertension medication, and having at least one VTE diagnosis were included. Adherence to OD and BID therapies was calculated by using two measures: medication possession ratio (MPR) and proportion of days covered (PDC). Adherence was defined as an MPR or PDC $\geq 0.8$. Multivariate logistic regressions were conducted to compare the probability of adherence between the OD and BID groups adjusting for baseline confounders.
\end{abstract}

Electronic supplementary material The online version of this article (doi:10.1007/s40271-013-0020-5) contains supplementary material, which is available to authorized users.

F. Laliberté $(\bowtie)$ · P. Lefebvre · J. Rondeau-Leclaire Groupe d'analyse, Ltée, 1000 rue de la Gauchetière Ouest, Bureau 1200, Montreal, QC H3B 4W5, Canada

e-mail: flaliberte@analysisgroup.com

B. K. Bookhart · W. W. Nelson · J. R. Schein

Janssen Scientific Affairs, LLC, Raritan, NJ, USA

M. S. Duh

Analysis Group, Inc., Boston, MA, USA
Results A total of 4,867 OD and 1,069 BID patients were identified. Mean duration of exposure to therapy for OD and BID patients was 386 and 356 days ( $p=0.011$ ), respectively. Based on MPR, $69 \%$ of OD and $62 \%$ of BID patients were adherent $(p<0.001)$. For PDC at 12 months, the proportion of adherent patients for the OD and BID groups was 45 and $36 \%(p<0.001)$, respectively. Adjusted odds ratios $(95 \%$ CI) of adherence for the OD relative to BID group were 1.61 $(1.37-1.89)$ based on MPR $(p<0.001)$ and $1.46(1.16-1.83)$ based on PDC at 12 months $(p=0.001)$.

Conclusions This study demonstrates that VTE patients treated with chronic medications on OD dosing regimens were associated with an approximately 39-61\% higher likelihood of adherence compared with subjects on BID dosing regimens.

\section{Key Points for Decision Makers}

- Prior to the current study, no other study had evaluated the relationship between medication adherence and daily dosing in patients with venous thromboembolism (VTE), and due to short half-lives, some medications used to treat VTE patients require strict adherence

- This study shows that VTE patients treated with oncedaily dosing regimens for chronic medications were associated with an approximately 39-61\% higher likelihood of adherence compared with subjects on twice-daily regimens

\section{Introduction}

Adherence to chronic medications has been described in the general population [1]; however, no study has evaluated 
the relationship between medication adherence and daily dosing in patients with venous thromboembolism (VTE). Due to short half-lives, some medications used to treat VTE patients require strict adherence; hence, the topic is especially relevant in this population [2-4].

VTE, which comprises deep vein thrombosis (DVT) and pulmonary embolism (PE), is a major health problem with approximately 900,000 incident cases annually in the United States (US), including 600,000 occurring in the hospital [5]. Almost 300,000 deaths annually have been attributed to PE in the US [5]; 2-10\% of all hospital deaths are associated with PE $[6,7]$ and up to $25 \%$ of all PE cases result in sudden death $[8,9]$. VTE patients are also at high risk of developing complications such as VTE recurrence, post-thrombotic syndrome, and chronic thromboembolic pulmonary hypertension.

Recent meta-analyses $[10,11]$ have assessed the association between adherence and daily dose frequency for oncedaily (OD) versus twice-daily (BID) regimens, reporting a 7-23\% higher adherence for OD versus BID regimens, but data specific to VTE patients are lacking. Studies have also shown that treatment adherence is an important consideration for VTE patients. It has been estimated that nearly a quarter of patients receive anticoagulant therapy for less than the recommended length of time after hospital discharge and that $12 \%$ of patients discontinue within 3 months [12, 13]. Moreover, given the unique comorbidity profile of the VTE population (e.g., many subjects had a prior surgery or other risk factors such as cancer, infections, chronic heart failure, and chronic lung disease) [14-18], and the severity of a VTE event and its possible complications, the assessment of adherence to OD and BID regimens for this specific population is of particular interest considering the common use of chronic medications for VTE patients. To fill this gap in the literature, the current study compares real-world adherence rates between OD and BID antidiabetics and antihypertensives in patients with VTE.

\section{Patients and Methods}

\subsection{Data Source}

Health insurance claims from the PharMetrics database between 1 January 2004, and 31 December 2009, were used to conduct the analysis. The PharMetrics Integrated Database is the largest nonpayer-owned integrated claims database of commercial insurers in the US. This de-identified, integrated database includes medical and pharmacy claims for more than 55 million unique members from more than 90 health plans across the US. Data elements include inpatient and outpatient claims, diagnoses and procedures based on ICD-9 and CPT-4 codes, as well as retail and mail order pharmacy claims. The records in the PharMetrics Integrated Database are representative of the national commercially insured population and include a variety of demographic measures such as age, gender, and plan type. This longitudinal data has an average member enrollment period of 2 years [19].

\subsection{Study Design}

A retrospective longitudinal cohort design was used where adult patients with VTE initiating an oral OD or BID regimen of antidiabetic or antihypertensive medications were identified. To be included in the study sample, patients were required to meet the following criteria: (a) have at least two OD or BID dispensings of antidiabetics, antihypertensives, calcium channel blockers, diuretics, or other hypertension medications, (b) be at least 18 years of age at the index date, (c) have at least 180 days of continuous enrollment before the index date (baseline period), and (d) have at least one primary or secondary diagnosis of VTE (ICD-9-Clinical Modification [CM] codes 451.1x, 451.2, 453.4x and 453.9 [DVT], and 415.1x [PE]) during the baseline period. No diagnosis of diabetes or hypertension was required. VTE patients with any other antidiabetic or antihypertensive medications (e.g., three times daily (TID), four times daily (QID), or from any other route of administration) during the 180-day baseline period or patients initiated on both OD and BID medications at the index date were excluded.

The observation period of patients spanned from the index date through the earliest date between a switch to an agent in another drug class (e.g., switch from a biguanide antidiabetic agent to a sulfonylureas antidiabetic agent), health plan disenrollment, and end of data availability (31 December 2009). Using an intent-to-treat approach (ITT), switches from the initial agent to another agent inside the same drug class were permitted regardless of the daily dosing frequency of the new agent the patient switched to.

\subsection{Definition of Medication Adherence and Persistence}

Adherence to OD and BID dosing regimens was estimated using the medication possession ratio (MPR) and the proportion of days covered (PDC). The MPR measure assessed the days of supply (i.e., the number of days a prescription is supposed to last) of each dispensing with the entire exposure to the treatment. The exposure to therapy was defined as the number of days between the date of the first drug fill and that of the last drug refill, plus the number of days of supply of that last refill. The MPR was then defined as the sum of the medication days of supply divided by the exposure to therapy [20]. The PDC differs from the MPR by being measured over fixed periods of time, namely 3,6 , 
12, and 18 months for this study. The PDC was calculated as the sum of the medication days of supply divided by the number of days evaluated at 3, 6, 12, and 18 months after the index date [1]. Adequate medication adherence was defined as an MPR or PDC $\geq 0.8$ [21]. Persistence was also calculated, defined as continuous use of the index medication without a gap of $\geq 30$ days between medication refills, that is, between the end of the days of supply of a dispensing and the following dispensing, at any time after treatment initiation [20]. When an overlap occurred between a new dispensing and the end of the previous dispensing, and this overlap was no more than seven days, the assumption was made that the prior supply was taken fully before the initiation of the new supply. If an overlap of more than 7 days occurred between two dispensings, no adjustment was made and the second medication was considered as initiated immediately.

\subsection{Statistical Analyses}

Univariate descriptive statistics were generated for the OD and BID groups. Frequency counts and percentages were used to summarize categorical variables. Mean values \pm SD were used to present normally distributed continuous variables. Data that are often skewed such as costs were reported with medians and interquartile ranges (median, Q1-Q3). Statistical differences between both populations were assessed using Chi-square tests (categorical variables) and Student's $t$ tests (continuous variables). Nonparametric statistics (i.e., Wilcoxon signed-rank test) were estimated for the analysis of skewed variables. Kaplan-Meier estimates and log-rank tests were performed to compare the persistence rates at different points in time $(3,6,12$, and 18 months).

Multivariate logistic regressions were also conducted to compare the probability of adherence between the OD and BID groups adjusting for observation period, age, gender, regions, year of index date, index medication (antidiabetics, angiotensin-converting enzyme [ACE] inhibitors/ angiotensin receptor blockers [ARBs], calcium channel blockers, diuretics, or beta-blockers), Charlson Comorbidity Index, baseline pill burden (number of pills per day [the number of pills dispensed during the 180-day baseline period divided by 180 days] and number of different drug entities), co-pay amount per dispensing, baseline healthcare costs (hospitalizations, outpatient visits, emergency room visits, and pharmacy dispensings), and baseline diabetes and hypertension diagnosis.

Furthermore, stratified analyses were conducted on the study population based on the type of VTE at baseline (DVT only or PE with or without DVT). A two-sided alpha level of 0.05 was used to declare statistical significance. All statistical analyses were performed using SAS version 9.1 (SAS Institute, Inc., Cary, NC, USA).

\section{Results}

\subsection{Patient Characteristics}

A total of 4,867 OD and 1,069 BID patients with VTE initiating antidiabetic or antihypertensive medications met the inclusion criteria and formed the study populations (Fig. 1). Table 1 describes the baseline characteristics of the study populations. The mean age (median; SD) for the OD and the BID group was $52.2(50 ; 12.2)$ and 49.1 $(50 ; 12.9)$ years, respectively $(p<0.001) ; 54.3$ and $53.0 \%$ were females, respectively $(p=0.453)$. The index drug was mainly hypertension medications for both the OD $(94.4 \%)$ and the BID groups $(72.8 \%)$.

\subsection{Treatment Patterns and Medication Adherence}

Table 2 presents the treatment patterns and medication adherence of the OD and BID groups during the observation period. The mean (SD) duration of exposure to therapy for OD and BID patients was 386 (366) and 356 (345) days $(p=0.011)$, respectively.

Based on the MPR measurement, $69.2 \%$ of OD patients and $62.2 \%$ of BID patients were adherent (i.e., MPR $\geq 0.8$; $p<0.001)$. For PDC at 12 months, the proportion of adherent patients (i.e., PDC $\geq 0.8$ ) for the OD and BID groups was 44.7 and $36.3 \%$, respectively $(p<0.001)$. Other PDC measurements at 3, 6, 12, and 18 months were all significantly higher for the OD group relative to the BID group (OD vs. BID; 3 months: 64.2 vs. $57.8 \%$; 6 months: 53.8 vs. $46.2 \%$; 18 months: 40.5 vs. $30.1 \%$; all $p$ values $<0.001)$. The Kaplan-Meier rates of persistence to the index medication assessed from months 3 to 18 were all significantly higher (except the comparison at 3 months) for the OD group compared with the BID group, with rates from 68.5 to $31.1 \%$ and 66.1 to $24.9 \%$, respectively.

Figure 2 summarizes the results of the multivariate analyses comparing the probability of adherence between the OD and BID groups after adjusting for baseline confounding factors. The adjusted odds ratio (95\% CI) of adherence for the OD relative to BID group based on the MPR definition was 1.61 (1.37-1.89). Based on the PDC definition, the adjusted odds ratios $(95 \% \mathrm{CI})$ at $3,6,12$, and 18 months were 1.39 (1.18-1.64), 1.41 (1.18-1.69), 1.46 (1.16-1.83), and 1.51 (1.13-2.01), respectively. The odds ratio findings showed that patients initiated on OD dosing regimens were associated with a 39-61\% higher likelihood of medication adherence than patients initiated 
Fig. 1 Patients' disposition flow chart. BID twice daily, $D V T$ deep vein thrombosis, $H T N$ hypertension, $O D$ oncedaily, $P E$ pulmonary embolism, $V T E$ venous thromboembolism

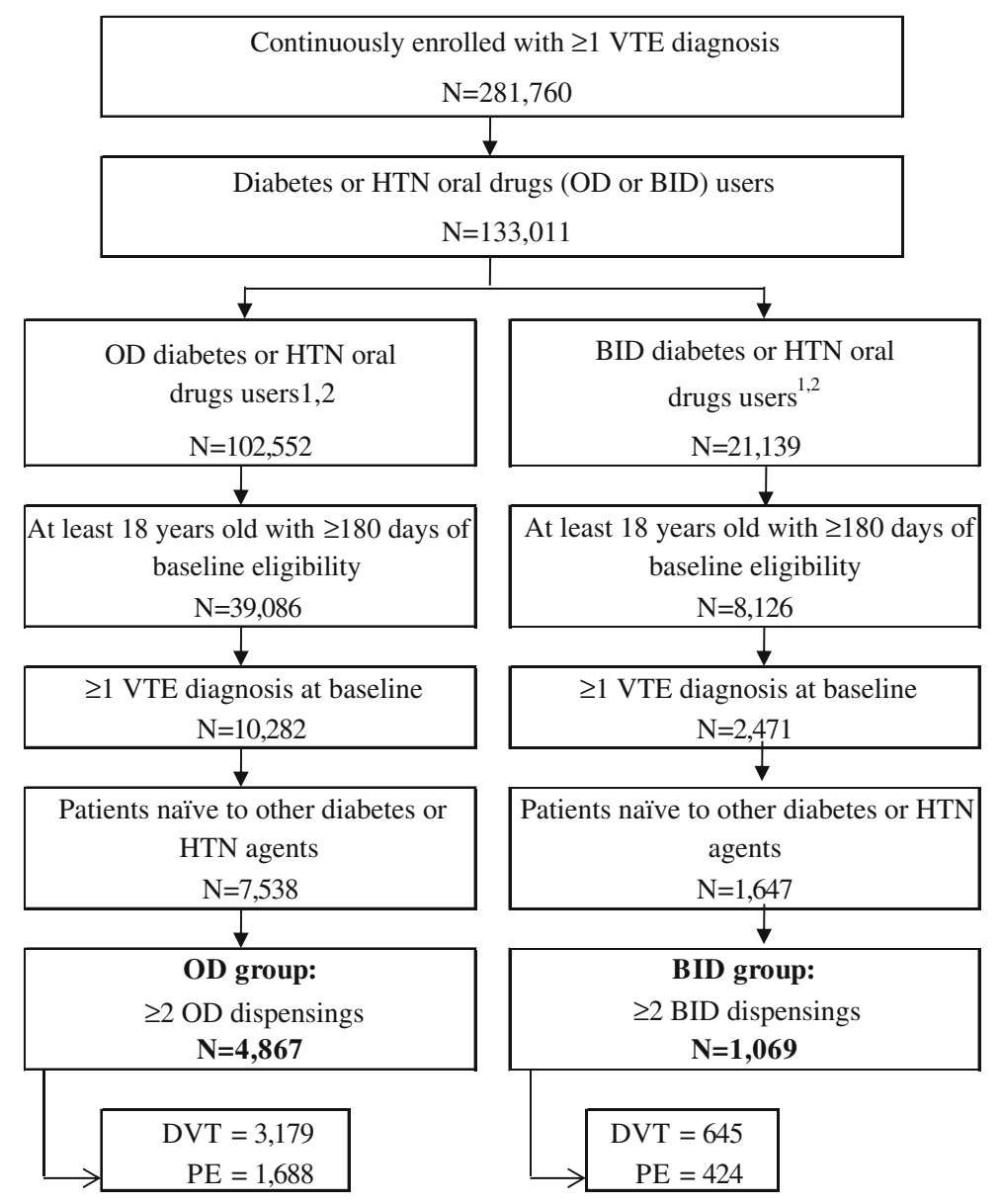

1. At least one prescription with a days of supply $\geq 28$ days.

2. Excluding patients initiated both on a OD and a BID on BID dosing regimens. Table 3 presents the complete regression model estimates for the MPR measurement.

Since an ITT approach was used in the current study, patients were allowed to switch dosing frequency within the drug class of the index medication. Among the OD cohort, $7.4 \%$ of patients switched at least once to a BID medication during the follow-up period, while in the BID group $18.4 \%$ of patients switched at least once to a OD medication $(p<0.001)$. The proportion of patients who switched dosing frequency during the follow-up period is reported in Table 4.

\subsection{Stratified Analysis by Type of VTE}

A total of 3,179 OD and 645 BID patients with DVT, and a total of 1,688 OD and 424 BID patients with PE formed the study populations of the stratified analysis. Table 5 presents the treatment patterns and medication adherence for the stratified analysis. Based on the MPR, patient adherence was higher for OD regimens as opposed to BID regimens in both subsets (DVT group: 68.0 vs. $61.2 \%$, $p=0.003$; PE group: 71.4 vs. $63.7 \%, p=0.002$ ). With the PDC measurements at $3,6,12$, and 18 months, a statistically higher medication adherence was found for the DVT subset for the OD compared with the BID group. For PE patients, although the adherence was higher for OD patients compared with BID patients with corresponding PDC measurements, statistical significance was only reached for the comparison at 6 months. Of note, the number of PE patients for the PDC measurements was much lower compared with the overall and the DVT subset analysis.

The adjusted odds ratios for the OD and BID group comparison stratified by type of VTE are presented in Fig. 2, while the complete regression model estimates for the MPR measurements are reported in the Electronic Supplementary Material. As measured by the MPR, DVT and PE patients treated with OD dosing regimens were both $62 \%$ more likely to adhere to treatment than those treated with BID dosing regimens, respectively $(p<0.001$ for both comparisons). PDCs at 3, 6, 12, and 18 months revealed a higher likelihood of adherence among DVT 
Table 1 Patient characteristics of the OD and BID study groups

\begin{tabular}{|c|c|c|c|}
\hline Patient characteristics & OD group & BID group & $p$ value \\
\hline Number of patients, $n$ & 4,865 & 1,069 & \\
\hline Observation period, days, mean $( \pm \mathrm{SD})$ & $509.21(420)$ & $472.99(385)$ & 0.006 \\
\hline \multicolumn{4}{|l|}{ Demographics } \\
\hline Age at index date, mean $( \pm \mathrm{SD})$ [median] & $52.2(12.2)[50.0]$ & $49.1(12.9)[50.0]$ & $<0.001$ \\
\hline Female, $n(\%)$ & $2,642(54.3)$ & $567(53.0)$ & 0.453 \\
\hline \multicolumn{4}{|l|}{ Region, $n(\%)$} \\
\hline Northeast & $1,243(25.5)$ & $241(22.5)$ & \multirow[t]{4}{*}{0.065} \\
\hline South & $1,117(23.0)$ & $230(21.5)$ & \\
\hline Midwest & $1,996(41.0)$ & $475(44.4)$ & \\
\hline West & $509(10.5)$ & $123(11.5)$ & \\
\hline \multicolumn{4}{|l|}{ Year of index date, $n(\%)$} \\
\hline 2004 & $351(7.2)$ & $75(7.0)$ & \multirow[t]{6}{*}{0.623} \\
\hline 2005 & $789(16.2)$ & $156(14.6)$ & \\
\hline 2006 & $914(18.8)$ & $201(18.8)$ & \\
\hline 2007 & $1,081(22.2)$ & $230(21.5)$ & \\
\hline 2008 & $1,096(22.5)$ & $264(24.7)$ & \\
\hline 2009 & $634(13.0)$ & $143(13.4)$ & \\
\hline \multicolumn{4}{|l|}{ Index medication, $n(\%)$} \\
\hline Diabetes medications & $273(5.6)$ & $291(27.2)$ & \\
\hline Biguanides & $125(2.6)$ & $227(21.2)$ & \multirow[t]{4}{*}{$<0.001$} \\
\hline Sulfonylurea & $71(1.5)$ & $31(2.9)$ & \\
\hline Thiazolidinedione & $55(1.1)$ & $6(0.6)$ & \\
\hline Other diabetes medications & $22(0.5)$ & $27(2.5)$ & \\
\hline Hypertension medications & 4,592 (94.4) & $778(72.8)$ & \\
\hline ACE inhibitors/ARBs & $1,643(33.8)$ & $103(9.6)$ & \multirow[t]{4}{*}{$<0.001$} \\
\hline Beta-blockers & $920(18.9)$ & $498(46.6)$ & \\
\hline Calcium channel blockers & $505(10.4)$ & $28(2.6)$ & \\
\hline Diuretics & $1,524(31.3)$ & 149 (13.9) & \\
\hline Charlson comorbidity index ${ }^{\mathrm{a}}$, mean $( \pm \mathrm{SD})$ & $1.46(2.33)$ & $1.99(2.6)$ & $<.001$ \\
\hline \multicolumn{4}{|l|}{ Charlson comorbidity index distribution ${ }^{\mathrm{a}}, n(\%)$} \\
\hline 0 & $2,313(47.5)$ & $346(32.4)$ & \\
\hline 1 & $1,106(22.7)$ & $299(28.0)$ & \\
\hline 2 & $591(12.1)$ & $164(15.3)$ & \\
\hline 3 & $288(5.9)$ & $72(6.7)$ & \\
\hline 4 & $153(3.1)$ & $52(4.9)$ & \\
\hline 5 or more & $414(8.5)$ & $136(12.7)$ & \\
\hline \multicolumn{4}{|l|}{ Other condition $^{\mathrm{a}}$} \\
\hline Hypertension & $2,254(46.3)$ & $399(37.3)$ & $<0.001$ \\
\hline Diabetes & $546(11.2)$ & $240(22.5)$ & $<0.001$ \\
\hline \multicolumn{4}{|l|}{ Baseline pill burden $^{\mathrm{a}}, n(\%)$} \\
\hline \multicolumn{4}{|l|}{ Mean number of pills per day ${ }^{b}$} \\
\hline 0 & $804(16.5)$ & $210(19.6)$ & \multirow[t]{5}{*}{0.073} \\
\hline$>0-1$ & $1,401(28.8)$ & $317(29.7)$ & \\
\hline$>1-2$ & $802(16.5)$ & $171(16.0)$ & \\
\hline$>2-3$ & $510(10.5)$ & $96(9.0)$ & \\
\hline$>3$ & $1,348(27.7)$ & $275(25.7)$ & \\
\hline
\end{tabular}


Table 1 continued

\begin{tabular}{|c|c|c|c|}
\hline Patient characteristics & OD group & BID group & $p$ value \\
\hline \multicolumn{4}{|c|}{ Number of different drug entities ${ }^{c}$} \\
\hline 0 & $804(16.5)$ & $210(19.6)$ & \multirow[t]{4}{*}{0.049} \\
\hline 1 & $3,033(62.3)$ & $627(58.7)$ & \\
\hline 2 & $704(14.5)$ & $152(14.2)$ & \\
\hline 3 or more & $324(6.7)$ & $80(7.5)$ & \\
\hline \multicolumn{4}{|c|}{ Baseline healthcare costs ${ }^{\mathrm{a}}$, US dollars, mean (Q1|Med|Q3) } \\
\hline Hospitalizations & $14,685(0|0| 10,757)$ & $31,282(0|4,773| 23,763)$ & $<0.001$ \\
\hline Pharmacy dispensings & $1,243(11|202| 909)$ & $1,072(3|171| 834)$ & 0.195 \\
\hline Emergency room visits & $404(0|0| 263)$ & $520(0|0| 345)$ & 0.170 \\
\hline Outpatient visits & $6,100(432|1,597| 4,613)$ & $6,351(385|1,555| 5,112)$ & 0.634 \\
\hline
\end{tabular}

${ }^{\text {a }}$ Based on the 180-day baseline period prior to the index date

${ }^{\mathrm{b}}$ Defined as the total number of pills dispensed during the 180-day baseline period divided by 180 days for each patient

${ }^{c}$ Defined as the mean number of different brands per patient dispensed during the 180-day baseline period

$A C E$ angiotensin-converting enzyme, $A R B s$ angiotensin receptor blockers, $B I D$ twice daily, Med median, $O D$ once-daily, $Q 1$ interquartile $1, Q 3$ interquartile 3

Table 2 Treatment patterns, adherence and persistence for overall population
${ }^{a}$ The exposure to therapy was defined as the number of days between the first dispensing and the last dispensing plus the days of supply of the last refill

$B I D$ twice daily, MPR medication possession ratio, $O D$ once-daily, $P D C$ proportion of days covered

\begin{tabular}{|c|c|c|c|}
\hline Variables & OD group $(N=4,865)$ & BID group $(N=1,069)$ & $p$ value \\
\hline \multicolumn{4}{|l|}{ Treatment patterns, mean $( \pm \mathrm{SD})$} \\
\hline Exposure to therapy ${ }^{\mathrm{a}}$, days & $386.4(366)$ & $356.4(345)$ & 0.011 \\
\hline Number of dispensings per patient & $9.4(9.85)$ & $8.9(9.51)$ & 0.119 \\
\hline Days of supply per dispensing & $35.1(18.65)$ & $33.1(15.98)$ & $<0.001$ \\
\hline Mean co-pay amount per prescription, US\$ & $12.4(17.15)$ & $10.7(18.57)$ & 0.006 \\
\hline \multicolumn{4}{|l|}{ Mean co-pay amount per prescription, $n(\%)$} \\
\hline$<\mathrm{US} \$ 10 \$$ & $2,954(60.69)$ & $681(63.7)$ & \multirow[t]{4}{*}{$<0.001$} \\
\hline US\$10-24 & $1,240(25.48)$ & $308(28.81)$ & \\
\hline US\$25-39 & $378(7.77)$ & $43(4.02)$ & \\
\hline$\geq \mathrm{US} \$ 40$ & $295(6.06)$ & $37(3.46)$ & \\
\hline \multicolumn{4}{|l|}{ Adherence } \\
\hline \multicolumn{4}{|l|}{ Based on exposure period ${ }^{\mathrm{a}}$} \\
\hline MPR, mean [median] & $0.82[0.91]$ & $0.80[0.88]$ & 0.001 \\
\hline$\%$ compliant patients (MPR $\geq 0.8$ ) & 69.2 & 62.2 & $<0.001$ \\
\hline \multicolumn{4}{|l|}{ At 3 months $(n=2,415 ; n=487)$} \\
\hline PDC, mean [median] & $0.83[0.93]$ & $0.80[0.88]$ & $<0.001$ \\
\hline$\%$ compliant patients $(\mathrm{PDC} \geq 0.8$ ) & 64.2 & 57.8 & $<0.001$ \\
\hline \multicolumn{4}{|l|}{ At 6 months $(n=1,497 ; n=276)$} \\
\hline PDC, mean [median] & $0.73[0.83]$ & $0.70[0.76]$ & 0.002 \\
\hline$\%$ compliant patients $(\mathrm{PDC} \geq 0.8)$ & 53.8 & 46.2 & $<0.001$ \\
\hline \multicolumn{4}{|l|}{ At 12 months $(n=741 ; n=130)$} \\
\hline PDC, mean [median] & $0.65[0.74]$ & $0.60[0.66]$ & 0.003 \\
\hline$\%$ compliant patients $(\mathrm{PDC} \geq 0.8$ ) & 44.7 & 36.3 & $<0.001$ \\
\hline \multicolumn{4}{|l|}{ At 18 months $(n=417 ; n=59)$} \\
\hline PDC, mean [median] & $0.60[0.66]$ & $0.56[0.61]$ & 0.043 \\
\hline$\%$ compliant patients (PDC $\geq 0.8$ ) & 40.5 & 30.1 & $<0.001$ \\
\hline \multicolumn{4}{|l|}{ Persistence, $\%$} \\
\hline 3 months & 68.5 & 66.1 & 0.108 \\
\hline 6 months & 53.6 & 46.2 & $<0.001$ \\
\hline 12 months & 38.1 & 32.3 & $<0.001$ \\
\hline 18 months & 31.1 & 24.9 & $<0.001$ \\
\hline
\end{tabular}




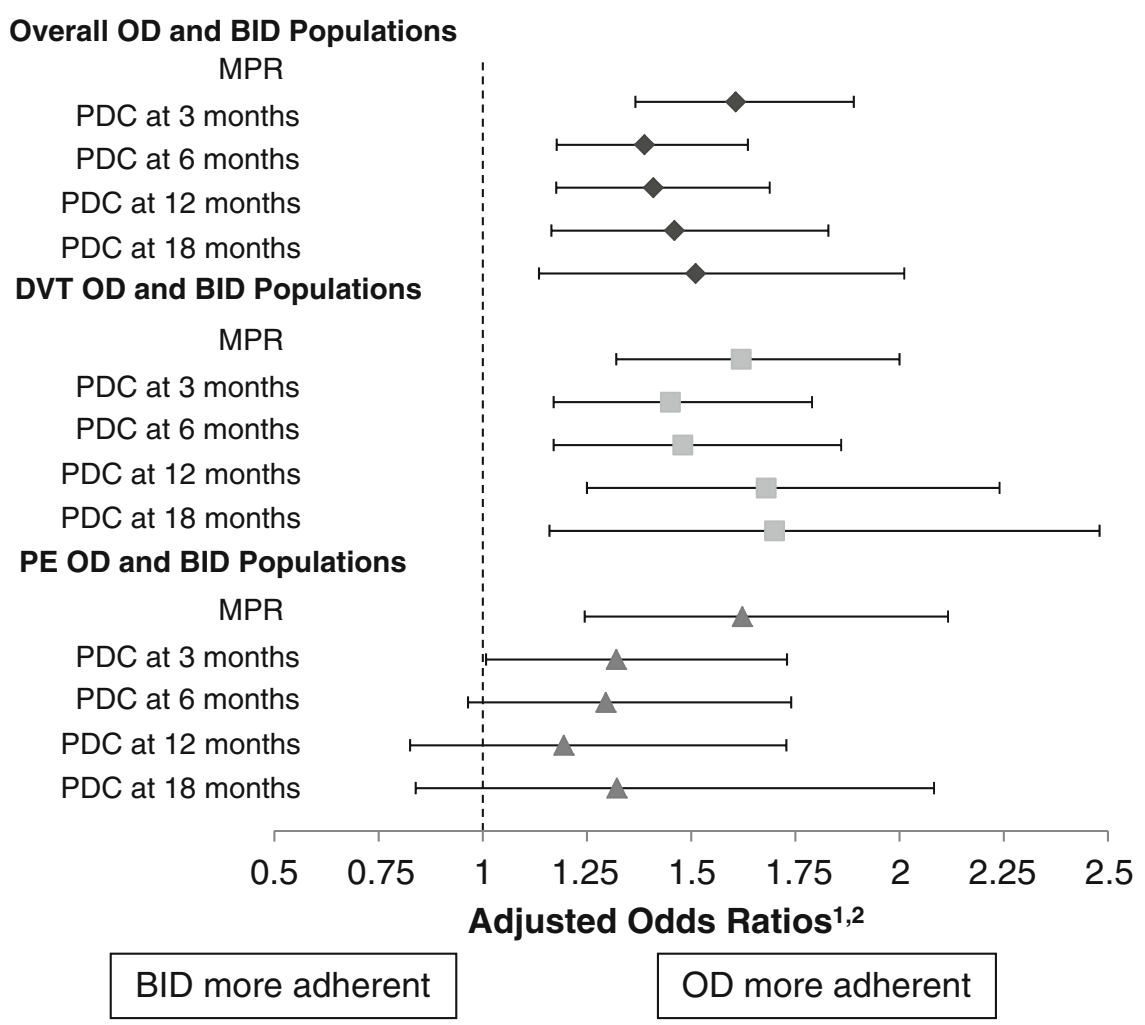

1. An adjusted odds ratio greater than one indicates that patients treated with OD dosing regimens were associated with a higher rate of medication adherence than those initiated on BID regimens after adjusting for baseline confounding factors. For example, an adjusted odds ratio of 1.20 indicates that patients in the OD group had a 20\% higher likelihood of medication adherence compared with patients initiated on BID regimens. The horizontal bars represent the $95 \%$ confidence intervals

2. Confounding factors adjusted for in the multivariate logistic regression models included the follow-up period age, gender, regions, year of index date, index drug (antidiabetics, antihypertensives, calcium channel blockers, diuretics, or other hypertension medications), Charlson comorbidity index (categorical variable), diabetes and hypertension at baseline, baseline pill burden (number of pills per day and number of different drug entities), copay amount per dispensing (categorical variables), and baseline healthcare costs (hospitalizations, outpatient visits, emergency room, and pharmacy dispensings)

Fig. 2 Multivariate logistic regressions modeling the adjusted probability of adherence for the OD relative to BID group. BID twice daily, $D V T$ deep vein thrombosis, $M P R$ medication possession ratio, $O D$ once-daily, $P D C$ proportion of days covered, $P E$ pulmonary embolism

patients with OD dosing regimens over BID dosing regimens of $45 \% \quad(p<0.001), 48 \% \quad(p<0.001), 68 \%$ $(p<0.001)$, and $70 \%(p=0.006)$, respectively. Among PE patients, the likelihood of adherence at 3,6,12, and 18 months was also greater for the OD versus BID patients; however, most of the PDC measurements did not reach statistical significance.

\section{Discussion}

Pharmacotherapy complexity is associated with reduced medication adherence [22]. Compared with the general population, VTE patients often have extensive operative procedures and a higher disease burden [17, 18], and they are also susceptible to experiencing various VTE-related adverse events such as VTE recurrence, post-thrombotic syndrome, and pulmonary hypertension [23-26]. The VTE population is thus susceptible to experiencing various adverse events that may be prevented by choosing treatments that will reduce therapy complexity.

In this large retrospective study based on real-world data, we found that VTE patients treated with OD therapy had a 39-61\% higher likelihood of medication adherence compared with comparable subjects on BID regimens, regardless of whether MPR or PDC was used as the definition for adherence. Using an intent-to-treat approach, this study allowed VTE patients to change daily dosing frequency during the follow-up to represent real-world usage of a patient initiating OD and BID regimens. Despite the possible change in daily dosing regimens, patients initiating a OD treatment were more likely to be adherent 
Table 3 Multivariate analysis: logistic regression model-modeling the probability of adherence (MPR $\geq 80 \%)^{\mathrm{a}}$

\begin{tabular}{llll}
\hline Variables & $\begin{array}{l}\text { Odds } \\
\text { ratio }\end{array}$ & $95 \% \mathrm{CI}$ & $p$ value \\
\hline
\end{tabular}

\begin{tabular}{|c|c|c|c|}
\hline \multicolumn{4}{|l|}{ Study groups } \\
\hline OD (ref.: BID)—unadjusted & 1.36 & $1.19-1.56$ & $<0.001$ \\
\hline OD (ref.: BID)—adjusted & 1.61 & $1.37-1.89$ & $<0.001$ \\
\hline Observation period (years: continuous) & 0.69 & $0.66-0.73$ & $<0.001$ \\
\hline \multicolumn{4}{|l|}{ Demographics } \\
\hline Age (years: continuous) & 1.02 & $1.01-1.02$ & $<0.001$ \\
\hline Female (ref: male) & 0.87 & $0.78-0.98$ & 0.025 \\
\hline \multicolumn{4}{|l|}{ Region (ref.: Northeast) } \\
\hline South & 0.90 & $0.76-1.06$ & 0.200 \\
\hline Midwest & 1.24 & $1.07-1.44$ & 0.004 \\
\hline West & 1.13 & $0.91-1.40$ & 0.264 \\
\hline \multicolumn{4}{|l|}{ Year of index date (ref.: 2009) } \\
\hline 2004 & 0.63 & $0.47-0.84$ & 0.002 \\
\hline 2005 & 0.83 & $0.65-1.07$ & 0.156 \\
\hline 2006 & 0.80 & $0.63-1.02$ & 0.072 \\
\hline 2007 & 0.71 & $0.57-0.89$ & 0.003 \\
\hline 2008 & 0.70 & $0.56-0.87$ & 0.001 \\
\hline \multicolumn{4}{|l|}{ Index drug (ref.: beta-blockers) } \\
\hline Antidiabetics & 0.83 & $0.65-1.05$ & 0.124 \\
\hline ACE inhibitors/ARBs & 0.95 & $0.80-1.13$ & 0.550 \\
\hline Calcium channel blockers & 1.02 & $0.80-1.31$ & 0.844 \\
\hline Diuretics & 0.53 & $0.45-0.63$ & $<0.001$ \\
\hline \multicolumn{4}{|l|}{ Charlson comorbidity index ${ }^{\mathrm{b}}$ (ref.: 0 ) } \\
\hline 1 & 0.89 & $(0.76-1.03)$ & 0.118 \\
\hline 2 & 1.14 & $(0.94-1.38)$ & 0.199 \\
\hline 3 & 0.91 & $(0.70-1.18)$ & 0.483 \\
\hline 4 & 0.83 & $(0.59-1.17)$ & 0.277 \\
\hline 5 or more & 1.09 & $(0.85-1.41)$ & 0.497 \\
\hline \multicolumn{4}{|l|}{ Other comorbidities ${ }^{\mathrm{b}}$} \\
\hline Diabetes & 1.09 & $(0.88-1.33)$ & 0.431 \\
\hline Hypertension & 0.97 & $(0.86-1.10)$ & 0.656 \\
\hline \multicolumn{4}{|l|}{ Baseline pills burden ${ }^{\mathrm{b}}$ (continuous) } \\
\hline Number of pills per day & 1.02 & $(1.00-1.03)$ & 0.078 \\
\hline Number of different drug entities & 0.99 & $(0.93-1.06)$ & 0.766 \\
\hline \multicolumn{4}{|c|}{ Co-pay amount per prescription (ref: $<$ US $\$ 10$ ) } \\
\hline US\$10-24 & 1.16 & $1.01-1.34$ & 0.033 \\
\hline US\$25-39 & 1.06 & $0.84-1.34$ & 0.627 \\
\hline$\geq \mathrm{US} \$ 40$ & 1.16 & $0.88-1.52$ & 0.286 \\
\hline \multicolumn{4}{|l|}{$\begin{array}{l}\text { Baseline healthcare costs }{ }^{\mathrm{b}} \text { (US\$000; } \\
\text { continuous) }\end{array}$} \\
\hline Hospitalizations & 1.00 & $1.00-1.01$ & $<0.001$ \\
\hline Pharmacy prescriptions & 0.99 & $0.98-1.01$ & 0.449 \\
\hline Emergency room visits & 0.98 & $0.95-1.02$ & 0.343 \\
\hline Outpatient visits & 1.00 & $0.99-1.00$ & 0.463 \\
\hline
\end{tabular}

$A C E$ angiotensin-converting enzyme, $A R B s$ angiotensin receptor blockers, $B I D$ twice a day, MPR medication possession ratio, $O D$ once a day

${ }^{a}$ The Hosmer and Lemeshow goodness of fit $p$ value is 0.571 , suggesting that the fitted model is an adequate model

b Based on an observation period of 180 days prior to index date compared with BID users. This finding was robust over time (3-18 months) and was observed with both MPR and PDC methods. Similar trends were also observed in stratified analyses by type of VTE (DVT only or PE with and without DVT).

Hypertension and diabetes are relatively 'silent' (i.e., asymptomatic) diseases, while VTE patients treated with anticoagulation medication, on the other hand, typically have symptomatic disease (proximal DVT or PE) and they are often well aware of the possible serious short-term consequences (e.g., VTE recurrence) of not taking their anticoagulant medication. However, even if the adherence to the initial treatment of a VTE event (e.g., parenteral anticoagulant) might be higher, patients are usually discharged from hospital with a prescription of oral anticoagulant to reduce the incidence of recurrent VTE, and the longer-term adherence to therapy post-discharge is a concern in the VTE community. An article by Ganz and colleagues [12] showed that nearly a quarter of anticoagulated patients following DVT or PE received therapy for less than the recommended length of time after hospital discharge. Deitelzweig and colleagues [13] found that $12 \%$ of patients discontinued warfarin within 3 months and treatment discontinuation was identified as a significant predictor of recurrent VTE. Of note, a life-threatening condition such as PE might lead to a better adherence from patients. In the study by Ganz and colleagues [12], PE patients were less likely to have inadequate duration of therapy in comparison with those with DVT (odds ratio $0.58,95 \%$ CI $0.38-0.88$ ). Considering the asymptotic nature of diabetes and hypertension, the current study on the adherence to antihypertensive and antidiabetic drugs only allowed indirect conclusions to be drawn regarding VTE patients' adherence to other chronic medications. Further research is warranted to assess if a better adherence for OD versus BID medication is found for other types of medications in VTE patients and if there is a difference between DVT and PE patients.

In the current study, around $20 \%$ of the population was initiated on BID therapy, which is an important proportion of chronic drug users. This study highlighted the difference in adherence among VTE patients using OD and BID chronic medications, which could have an impact on possible adverse events related to non-adherence. Further research will be required to examine the impact of adherence on clinical outcomes. Non-adherence can cause adverse outcomes such as relapse of the disease being treated, nursing home admission, and hospitalization [2730], and it has been estimated that 33-69 \% of all medication-related hospital admissions are due to poor medication adherence [27]. Of note, adherence with OD regimens was also suboptimal in the current study. Adherence is a multifactorial process and changing the 
Table 4 Daily dosing frequency switches within the drug class of the index medication for the OD and BID study groups

\begin{tabular}{|c|c|c|c|}
\hline Daily dosing frequency change during the follow-up period & OD group & BID group & $p$ value \\
\hline$\geq 1$ BID (OD group) or $\geq 1$ OD (BID group), $\%$ [A] & $358 / 4,867(7.36 \%)$ & 197/1,069 (18.43\%) & $<0.001$ \\
\hline $0-3$ months & $172 / 4,867(3.53 \%)$ & $85 / 1,069(7.95 \%)$ & $<0.001$ \\
\hline 4-6 months & $162 / 3,602(4.50 \%)$ & $97 / 790(12.28 \%)$ & $<0.001$ \\
\hline $7-12$ months & $165 / 2,777(5.94 \%)$ & $95 / 592(16.05 \%)$ & $<0.001$ \\
\hline $13-18$ months & $122 / 1,725(7.07 \%)$ & 77/357 (21.57\%) & $<0.001$ \\
\hline$\geq 1$ TID or QID, $\%[B]$ & $75 / 4,867(1.54 \%)$ & $85 / 1,069(7.95 \%)$ & $<0.001$ \\
\hline $0-3$ months & $33 / 4,867(0.68 \%)$ & $49 / 1,069(4.58 \%)$ & $<0.001$ \\
\hline $4-6$ months & $46 / 3,602(1.28 \%)$ & $45 / 790(5.70 \%)$ & $<0.001$ \\
\hline $7-12$ months & $40 / 2,777(1.44 \%)$ & $43 / 592(7.26 \%)$ & $<0.001$ \\
\hline 13-18 months & $17 / 1,725(0.99 \%)$ & $39 / 357(10.92 \%)$ & $<0.001$ \\
\hline$\geq 1$ different daily dosing frequency, $\%$ ([A] or $[\mathrm{B}])$ & $405 / 4,867(8.32 \%)$ & $275 / 1,069(25.72 \%)$ & $<0.001$ \\
\hline $0-3$ months & $200 / 4,867(4.11 \%)$ & $134 / 1,069(12.54 \%)$ & $<0.001$ \\
\hline 4-6 months & $198 / 3,602(5.50 \%)$ & 142/790 (17.97\%) & $<0.001$ \\
\hline $7-12$ months & $194 / 2,777(6.99 \%)$ & $138 / 592(23.31 \%)$ & $<0.001$ \\
\hline 13-18 months & 137/1,725 (7.94 \%) & $113 / 357(31.65 \%)$ & $<0.001$ \\
\hline
\end{tabular}

[A] switch within the drug class of the index medication to a BID (OD group) or to a OD (BID group) medication, [B] switch within the drug class of the index medication to a TID or a QID medication

$B I D$ twice a day, $O D$ once a day, $Q I D$ four times a day, $T I D$ three times a day

dosing frequency can only partially improve adherence. Factors that may affect patient adherence have been classified as modifiable or nonmodifiable [31]. Nonmodifiable factors include the asymptomatic nature of a disease that may cause patients to forget about their condition, while modifiable factors include the number of medications prescribed, daily dosing frequency, and complexity of administration (e.g., parenteral, oral). A multi-faceted approach to improving adherence is thus needed.

Recent studies have evaluated the medication adherence to OD relative to BID regimens using administrative claims [32-34]. Bae and colleagues [32] used administrative claims data from July 2006 to December 2008 to evaluate medication adherence to antidiabetic, antihyperlipidemic, antiplatelet, or cardiac agent therapy in more than 1 million patients. They found that a OD dosing regimen was related to a $16 \%$ higher MPR versus a BID regimen, with mean MPR of 0.66 and 0.57 , respectively $(p<0.01)$. A study by Toy and colleagues [33] using an administrative claims database from 1999 to 2006 showed that medication adherence to the initial drug treatment of chronic obstructive pulmonary disease (COPD) was associated with dosing frequency, with OD dosing having the highest adherence levels relative to BID, TID, or QID. Based on a sample of 55,076 COPD patients over 12 months of follow-up, the PDC was 43.3, 37.0, 30.2, and $23.0 \%$ for OD, BID, TID, and QID cohorts, respectively. The authors also showed a 22-26\% significantly higher likelihood of adherence to a OD compared with BID dosing regimen among patients with nonvalvular atrial fibrillation in a previous study [34].

The impact of OD versus BID regimens on medication adherence has also been evaluated in two recent metaanalyses of studies using electronic monitoring devices [10, 11]. Coleman and colleagues [10] reviewed the effect of dosing frequency on chronic cardiovascular disease medication adherence and found that adjusted mean adherences to BID and TID regimens was significantly lower by 7-23\% and 14-30\% (depending on the method used to determine adherence), respectively, compared with OD regimens. Coleman and colleagues also studied medication adherence in patients with chronic diseases and found that adjusted mean adherence to BID, TID, and QID regimens was significantly lower by $7-27 \%, 14-39 \%$, and 19-54 \%, respectively, compared with a OD regimen [11]. Review articles have studied the impact of OD versus BID regimens on medication adherence, although most of the underlying data for these studies are based on the pre-2000 era. A systematic review by Saini and colleagues [35] on adherence in asymptomatic chronic disease, as assessed by medication event monitoring systems, reported that patients were more compliant with OD compared with BID regimens. Patients receiving OD dosing had 2-44\% more adherent days compared with patients receiving BID dosing, with most studies clustering around 13-26 \%; however, because of differences in study design, study population, and data reporting no attempt was made to combine these results into a meta-analysis. Iskedjian and 
Table 5 Treatment patterns, adherence and persistence for DVT and PE patients

\begin{tabular}{|c|c|c|c|c|c|c|}
\hline \multirow[t]{2}{*}{ Variables } & \multicolumn{3}{|c|}{ DVT population } & \multicolumn{3}{|l|}{ PE population } \\
\hline & $\begin{array}{l}\text { OD group } \\
(N=3,179)\end{array}$ & $\begin{array}{l}\text { BID group } \\
(N=645)\end{array}$ & $p$ value & $\begin{array}{l}\text { OD group } \\
(N=1,688)\end{array}$ & $\begin{array}{l}\text { BID group } \\
(N=424)\end{array}$ & $p$ value \\
\hline \multicolumn{7}{|l|}{ Treatment patterns, mean $( \pm \mathrm{SD})$} \\
\hline Exposure to therapy, days & $388.64(362)$ & $367.31(347)$ & 0.170 & $382.16(372)$ & $339.77(341)$ & 0.025 \\
\hline $\begin{array}{l}\text { Number of dispensings per } \\
\text { patient }\end{array}$ & $9.42(9.70)$ & $9.22(9.76)$ & 0.646 & $9.44(10.12)$ & $8.43(9.11)$ & 0.046 \\
\hline Days of supply per dispensing & $35.47(18.91)$ & $32.99(16.16)$ & $<0.001$ & $34.55(18.12)$ & $33.30(15.71)$ & 0.158 \\
\hline $\begin{array}{l}\text { Mean co-pay amount per } \\
\text { prescription }\end{array}$ & $12.76(17.64)$ & $10.91(20.74)$ & 0.034 & $11.62(16.18)$ & $10.30(14.69)$ & 0.105 \\
\hline \multicolumn{7}{|c|}{ Mean co-pay amount per prescription, $n(\%)$} \\
\hline$<\mathrm{US} \$ 10$ & $1,904(59.89)$ & $400(62.02)$ & $<0.001$ & $1,050(62.2)$ & $281(66.27)$ & 0.102 \\
\hline US\$10-24 & $816(25.67)$ & $201(31.16)$ & & $424(25.12)$ & $107(25.24)$ & \\
\hline US\$25-39 & $254(7.99)$ & $21(3.26)$ & & $124(7.35)$ & $22(5.19)$ & \\
\hline $\mathrm{US} \$ \geq 40$ & $205(6.45)$ & $23(3.57)$ & & $90(5.33)$ & $14(3.3)$ & \\
\hline \multicolumn{7}{|l|}{ Adherence } \\
\hline \multicolumn{7}{|l|}{ Based on exposure period } \\
\hline MPR, mean [median] & $0.82[0.90]$ & $0.79[0.87]$ & 0.008 & $0.84[0.93]$ & $0.81[0.89]$ & 0.037 \\
\hline $\begin{array}{l}\% \text { compliant patients } \\
(\mathrm{MPR} \geq 0.8)\end{array}$ & 68.0 & 61.2 & 0.003 & 71.4 & 63.7 & 0.002 \\
\hline \multicolumn{7}{|c|}{ At 3 months $(n=2,882 ; n=583$ I $n=1,496 ; n=384)$} \\
\hline PDC, mean [median] & $0.82[0.93]$ & $0.79[0.87]$ & 0.003 & $0.84[0.94]$ & $0.81[0.89]$ & 0.011 \\
\hline $\begin{array}{l}\% \text { compliant patients } \\
\quad(\mathrm{PDC} \geq 0.8)\end{array}$ & 63.3 & 55.9 & 0.002 & 65.8 & 60.7 & 0.059 \\
\hline \multicolumn{7}{|c|}{ At 6 months $(n=2,407 ; n=493$ I $n=1,225 ; n=295)$} \\
\hline PDC, mean [median] & $0.73[0.83]$ & $0.69[0.76]$ & 0.012 & $0.73[0.83]$ & $0.70[0.78]$ & 0.055 \\
\hline $\begin{array}{l}\% \text { compliant patients } \\
\quad(\mathrm{PDC} \geq 0.8)\end{array}$ & 53.7 & 45.2 & 0.005 & 54.6 & 47.8 & 0.035 \\
\hline \multicolumn{7}{|c|}{ At 12 months $(n=1,660 ; n=338 \mid n=854 ; n=194)$} \\
\hline PDC, mean [median] & $0.64[0.74]$ & $0.59[0.66]$ & 0.008 & $0.65[0.74]$ & $0.61[0.65]$ & 0.159 \\
\hline $\begin{array}{l}\% \text { compliant patients } \\
\quad(\mathrm{PDC} \geq 0.8)\end{array}$ & 45.5 & 36.1 & 0.006 & 43.3 & 36.6 & 0.087 \\
\hline \multicolumn{7}{|c|}{ At 18 months $(n=1,157 ; n=208 \mid n=614 ; n=141)$} \\
\hline PDC, mean [median] & $0.60[0.66]$ & $0.56[0.63]$ & 0.107 & $0.60[0.66]$ & $0.57[0.57]$ & 0.208 \\
\hline $\begin{array}{l}\% \text { compliant patients } \\
\quad(\mathrm{PDC} \geq 0.8)\end{array}$ & 41.2 & 29.3 & 0.002 & 39.3 & 31.2 & 0.076 \\
\hline \multicolumn{7}{|l|}{ Persistence, $\%$} \\
\hline 3 months & 67.5 & 65.6 & 0.250 & 70.0 & 67.0 & 0.204 \\
\hline 6 months & 53.5 & 45.5 & 0.002 & 53.7 & 47.3 & 0.037 \\
\hline 12 months & 37.9 & 31.2 & 0.002 & 38.4 & 34.0 & 0.077 \\
\hline 18 months & 31.1 & 24.7 & 0.002 & 31.0 & 25.1 & 0.038 \\
\hline
\end{tabular}

$B I D$ twice daily, $D V T$ deep vein thrombosis, $M P R$ medication possession ratio, $O D$ once-daily, $P D C$ proportion of days covered, $P E$ pulmonary embolism

colleagues [30] conducted a meta-analysis and demonstrated that with antihypertensive medications, OD dosing therapy compared with either BID or multiple daily dose therapy was associated with higher rates of medication adherence. A systematic review by Claxton and colleagues [36] of studies reporting adherence measured by electronic monitoring devices, including published reports on several conditions (e.g., cardiovascular disease, respiratory disease, infectious disease, and cancer), reported that medication adherence was inversely proportional to dosing frequency. Adherence was significantly higher for OD versus TID and for OD versus QID regimens; however, there were no significant differences in adherence between $\mathrm{OD}$ and BID regimens. 
Other review articles of literature published between the 1970s and the 1990s could not reach a definitive conclusion on whether the simplification of dosing regimens was associated with better medication adherence [37-40]. The current study concurs with the most recent literature that patients were more compliant with OD compared with BID regimens [10, 11, 30, 32-35]. More up-to-date studies are warranted on the impact of daily dosing regimens on adherence given the serious consequences of nonadherence to chronic medications, such as hospital readmission [27] and other adverse outcomes.

This study was subject to several limitations. First, claims databases may contain inaccuracies or omissions in coded procedures, diagnoses, or pharmacy claims; however, it would be unlikely that these have significantly impacted our results considering the large sample size. Second, adherence to OD and BID regimens were assessed based on PDC, which may not reflect patients' actual adherence to medications. A claim for a prescription refill does not necessarily mean that a patient is taking the medication as prescribed, as some patients may obtain refills before a prescription runs out. However, in the current study if a claim for a new prescription overlapped with the end of the previous supply within a 7-day window, the beginning of the new prescription was delayed in order to minimize the early refill effect. Third, although we conducted multivariate analyses to account for baseline confounding factors between the OD and BID groups, omitted variable bias cannot be ruled out. For example, the current study used only prescribed medications since over-the-counter medications were not available in the database. Consequently, it was not possible to control for the impact that over-thecounter medication usage might have had on adherence levels. In addition, since the exposure to OD or BID medication was not randomly selected, there is the possibility of confounding by indication. Despite these limitations, well designed retrospective studies provide valuable information, with real-life scenarios and high generalizability.

\section{Conclusion}

This large real-world study of nearly 6,000 patients shows that patients with a history of thromboembolism (at least one primary or secondary diagnosis of VTE) treated with OD dosing regimens for chronic medications were associated with an approximately 39-61\% higher likelihood of adherence to therapy compared with subjects on BID dosing regimens. The findings were consistent across two methods of determining medication adherence.

Conflict of interest This research was funded by Janssen Scientific Affairs, LLC, Raritan, NJ, USA. Four of the authors (FL, PL, JRL,
MSD) are employees of Analysis Group, Inc., a consulting company that has received research grants from Janssen Scientific Affairs, LLC., and three of the authors (BKB, WWN, and JRS) are employees of Janssen Scientific Affairs, LLC.

Author contributions Study concept and design and data interpretation were primarily the work of BKB and MSD, with assistance from the other authors. FL performed the data collection with the assistance of JRL and PL. Writing of the manuscript was shared by FL, JRL, MSD, and PL. Revision of the manuscript was shared by $\mathrm{BKB}, \mathrm{WWN}$, and JRS. FL is the guarantor for the overall content.

Open Access This article is distributed under the terms of the Creative Commons Attribution Noncommercial License which permits any noncommercial use, distribution, and reproduction in any medium, provided the original author(s) and the source are credited.

\section{References}

1. Yeaw J, Benner JS, Walt JG, et al. Comparing adherence and persistence across 6 chronic medication classes. J Manag Care Pharm. 2009;15:728-40.

2. Schulman S, Crowther MA. How I treat with anticoagulants in 2012: new and old anticoagulants, and when and how to switch. Blood. 2012;119:3016-23.

3. Davis NJ, Billett HH, Cohen HW, Arnsten JH. Impact of adherence, knowledge, and quality of life on anticoagulation control. Ann Pharmacother. 2005;39:632-6.

4. Barcellona D, Contu P, Marongiu F. Patient education and oral anticoagulant therapy. Haematologica. 2002;87:1081-6.

5. Heit JA, Cohen AT, Anderson FA Jr, et al. Estimated annual number of incident and recurrent, non-fatal and fatal venous thromboembolism (VTE) events in the U.S [poster presented at: 47th annual meeting of the American Society of Hematology (ASH); December 10-14, 2005, Atlanta]. Blood. 2005;106:267a.

6. Sandler DA, Martin JF. Autopsy proven pulmonary embolism in hospital patients: are we detecting enough deep vein thrombosis? J R Soc Med. 1989;82:203-5.

7. Kopcke D, Harryman O, Benbow EW, et al. Mortality from pulmonary embolism is decreasing in hospital patients. J R Soc Med. 2011;104:327-31.

8. Heit JA. The epidemiology of venous thromboembolism in the community: implications for prevention and management. J Thromb Thrombolysis. 2006;21:23-9.

9. Kearon C. Natural history of venous thromboembolism. Circulation. 2003;107:I22-30.

10. Coleman CI, Roberts MS, Sobieraj DM, et al. Effect of dosing frequency on chronic cardiovascular disease medication adherence. Curr Med Res Opin. 2012;28:1-12.

11. Coleman CI, Limone B, Sobieraj DM, et al. Dosing frequency and medication adherence in chronic disease. J Manag Care Pharm. 2012;18:527-39.

12. Ganz DA, Glynn RJ, Mogun H, et al. Adherence to guidelines for oral anticoagulation after venous thrombosis and pulmonary embolism. J Gen Intern Med. 2000;15:776-81.

13. Deitelzweig SB, Lin J, Kreilick C, et al. Warfarin therapy in patients with venous thromboembolism: patterns of use and predictors of clinical outcomes. Adv Ther. 2010;27:623-33.

14. Goldhaber SZ, Elliott CG. Acute pulmonary embolism: part I: epidemiology, pathophysiology, and diagnosis. Circulation. 2003;108:2726-9.

15. Heit JA, Silverstein MD, Mohr DN, et al. The epidemiology of venous thromboembolism in the community. Thromb Haemost. $2001 ; 86: 452-63$. 
16. Leizorovicz A, Mismetti P. Preventing venous thromboembolism in medical patients. Circulation. 2004;110:13-9.

17. Agnelli G. Prevention of venous thromboembolism in surgical patients. Circulation. 2004;110:4-12.

18. Lefebvre P, Laliberté F, Nutescu EA, et al. All-cause and potentially disease-related health care costs associated with venous thromboembolism in commercial, Medicare, and Medicaid beneficiaries. J Manag Care Pharm. 2012;18:363-74.

19. IMS Health. IMS RxBenchmark: PharMetrics Integrated Database. http://www.imshealth.com/portal/site/ims/menuitem.d248e29c865 89c9c30e81c033208c22a/?vgnextoid=d6952a2e23264310VgnVC M100000ed152ca2RCRD\&vgnextchannel=c03c90916e442310V gnVCM100000ed152ca2RCRD (Accessed 30 May 2013).

20. Sikka R, et al. Estimating medication persistency using administrative claims data. Am J Manag Care. 2005;11:449-57.

21. Ho PM, et al. Medication adherence: its importance in cardiovascular outcomes. Circulation. 2009;2009(119):3028-35.

22. Choudhry NK, Fischer MA, Avorn J, et al. The implications of therapeutic complexity on adherence to cardiovascular medications. Arch Intern Med. 2011;171:814-22.

23. Prandoni $\mathrm{P}$, Lensing AWA, Cogo A, et al. The long-term clinical course of acute deep venous thrombosis. Ann Intern Med. 1996;125:1-7.

24. Prandoni P, Noventa F, Ghirarduzzi A, et al. The risk of recurrent venous thromboembolism after discontinuing anticoagulation in patients with acute proximal deep vein thrombosis or pulmonary embolism: a prospective cohort study in 1,626 patients. Haematologica. 2007;92:199-205.

25. Goldhaber SZ, Buonameaux H. Pulmonary embolism and deep vein thrombosis. Lancet. 2012;379:1835-46.

26. Hansson PO, Sorbo J, Eriksson H. Recurrent venous thromboembolism after deep vein thrombosis: incidence and risk factors. Arch Intern Med. 2000;160:769-74.

27. Ostenberg L, Blaschke T. Adherence to medication. N Engl J Med. 2005;353:487-97.

28. Iskedjian M, Addis A, Einarson T. Estimating the cost of hospital admissions due to patient nonadherence in Ontario, Canada. Pharmacoepidemiol Drug Saf. 1998;7:S92.

29. Psaty BM, Koepsell TD, Wagner EH, LoGerfo JP, Inui TS. The relative risk of incident coronary heart disease associated with recently stopping the use of beta-blockers. JAMA. 1990;263: 1653-7.

30. Iskedjian M, Einarson TR, MacKeigan LD, et al. Relationship between daily dose frequency and adherence to antihypertensive pharmacotherapy: evidence from a meta-analysis. Clin Ther. 2002;24:302-16.

31. Haynes RB, Taylor DW, Snow JC, et al. Appendix I: annotated and indexed bibliography on compliance with therapeutic and preventative regimens. In: Haynes RB, Taylor DW, Sackett DL, editors. Compliance in health care. Baltimore: The Johns Hopkins University Press; 1979. p. 337-43.

32. Bae JP, Dobesh PP, Klepser DG, et al. Adherence and dosing frequency of common medications for cardiovascular patients. Am J Manag Care. 2012;18:139-46.

33. Toy EL, Beaulieu NU, McHale JM, et al. Treatment of COPD: relationships between daily dosing frequency, adherence, resource use, and costs. Respir Med. 2011;105:435-41.

34. Laliberté F, Nelson WW, Lefebvre P, et al. Impact of daily dosing frequency on adherence to chronic medications among nonvalvular atrial fibrillation patients. Adv Ther. 2012;29: 675-90.

35. Saini SD, Schoenfeld P, Kaulback K, Dubinsky MC. Effect of medication dosing frequency on adherence in chronic diseases. Am J Manag Care. 2009; 15:e22-33.

36. Claxton AJ, Cramer J, Pierce C. A systematic review of the associations between dose regimens and medication compliance. Clin Ther. 2001;23:1296-310.

37. Greenberg RN. Overview of patient compliance with medication dosing: a literature review. Clin Ther. 1984;6:592-9.

38. Blackwell B. The drug regimen and treatment compliance. In: Haynes RB, Taylor DW, Sackett DL, editors. Compliance in health care. Baltimore: The Johns Hopkins University Press; 1979. p. 144-56.

39. Haynes RB. Determinants of compliance: the disease of the mechanics of treatment. In: Haynes RB, Taylor DW, Sackett DL, editors. Compliance in health care. Baltimore: The Johns Hopkins University Press; 1979. p. 49-63.

40. Reid J. Medication compliance in the elderly: a review. J Clin Exp Gerontol. 1985;7:31-49. 